\title{
Effective building materials using technogenic waste and mineral raw materials
}

\author{
Liliya Berdnikova ${ }^{1-}$, Fedor Gorbunov ${ }^{1,2}$, and Andrey Lapin ${ }^{2}$ \\ ${ }^{1}$ Institute of Solid State Chemistry and Mechanochemistry of SB RAS, 630128, 18, Kutateladze str., \\ Novosibirsk, Russia \\ ${ }^{2}$ Novosibirsk State Technical University, 630073, 20, K. Marx Ave., Novosibirsk, Russia
}

\begin{abstract}
The results of research on the development of compositions of construction materials for structural purposes based on technogenic waste and mineral raw materials are presented. The possibility of obtaining materials with a wide range of operational properties by the methods of slip casting (compressive strength of the samples based on chamotte and sand is $53.0-95.9$ and $50.0-69.5 \mathrm{MPa}$, bending strength is $8.1-16.5$ and $8.5-15.3 \mathrm{MPa}$, abrasion is $0.2-0.36$ and $0.15-0.39 \mathrm{~g} / \mathrm{cm}^{2}$, respectively) and semi-dry pressing (compressive strength of the samples based on chamotte and sand are 19.1-43.5 and 18.3-32.6 MPa respectively) is demonstrated.
\end{abstract}

\section{Introduction}

The most common types of refractory scrap - chamotte and dynas, the degree of processing of which in developed countries (Japan, China, USA) is an average of 50\%, in Russia it does not exceed 30\% [1-3]. However, even abroad on separate plants of ferrous metallurgy, the proportion of their burial ranges from 10 to $97 \%$ [2] due to the fact that most of the exhaust refractories are not used, and fall into dumps. This not only worsens the environmental situation, but is also not a good use of a sufficiently valuable resource.

Fireproof waste is non-toxic technogenic raw materials (a class of danger according to FCCW [4] - low hazardous waste), which can be used to produce new types of building materials/binders. This direction of processing of this type of raw material is especially effective, since it allows you to solve the problem of their disposal and reduces the anthropogenic impact on the environment. An important factor in the creation of energy and resource-saving technologies of building materials in the context of the ubiquity costs is also the integrated use of mineral resources and waste industry.

Therefore, the development of an effective building material with increased physicmechanical characteristics using firewall waste, both independent raw materials, and together with natural mineral raw materials is an urgent task, on the solution of which this study is directed. The prevalence of such mineral raw materials, like career sand, on the larger territory of Russia and a fairly intensive formation of firewall wastes suggest their integrated use to solve the task.

— Corresponding author: liliya baikina@mail.ru 


\section{Experimental}

To obtain samples of building materials, a silicate binder was used with a module 2 and a density of $1.3 \mathrm{~g} / \mathrm{cm}^{3}$, synthesized from the scrap of dynas refractory (dynas) of the resinmagnesia workshop WSMP LLC (Novokuznetsk). To obtain a binder with the specified silicate module, the pre-crushed to graininess $\leq 0.14 \mathrm{~mm}$ dynas was poured with a $17 \%$ solution of sodium hydroxide in the ratio of $\mathrm{S}: \mathrm{L}=1: 3 \mathrm{wt}$. h. Next, the mixture was subjected to heat treatment at $100^{\circ} \mathrm{C}$ for 6 hours with periodic stirring. The unreacted residue was removed by centrifugation. The resulting solution was evaporated to obtain a binding density of $1.3 \mathrm{~g} / \mathrm{cm}^{3}$. The method of synthesis of the binder was earlier reported by Berdnikova et al. [5].

Quarry sand and refractory scrap (chamotte), pre-crushed to a particle size of $\leq 0.14 \mathrm{~mm}$, were used as the fillers to produce the samples of building materials. Their chemical compositions are given in Table 1 .

Table 1. Chemical compositions of the used materials.

\begin{tabular}{|c|c|c|c|c|c|c|c|c|c|}
\hline \multirow{2}{*}{ Filler } & \multicolumn{8}{|c|}{ Component composition, wt.\% } \\
\cline { 2 - 10 } & $\mathrm{Na}_{2} \mathrm{O}$ & $\mathrm{MgO}$ & $\mathrm{Al}_{2} \mathrm{O}_{3}$ & $\mathrm{SiO}_{2}$ & $\mathrm{~K}_{2} \mathrm{O}$ & $\mathrm{CaO}$ & $\mathrm{TiO}_{2}$ & $\mathrm{Fe}_{2} \mathrm{O}_{3}$ & L.o.i.* \\
\hline Sand & 1.2 & - & 9.4 & 64.1 & 5.6 & 6.1 & - & 12.4 & 1.2 \\
\hline Chamotte & - & 0.7 & 30.5 & 50.8 & 1.7 & 2.3 & 3.6 & 10.4 & - \\
\hline
\end{tabular}

*L.o.i. - loss on ignition.

The molding of products was performed by the methods of slip casting or semi-dry pressing. In the first case, the mixer was covered with a filler, then a binder was added at the rate of $\mathrm{S}: \mathrm{L}=3.3: 1 \mathrm{wt}$. h., the mixture was thoroughly mixed until a homogeneous mass was obtained, and placed in steel molds. Next, the samples were subjected to step drying: first, they were kept at room temperature for 24 hours, and then at a temperature of no more than $50^{\circ} \mathrm{C}$ for $24-48$ hours. Heat treatment was carried out at a temperature of $150-700^{\circ} \mathrm{C}$ for 30 minutes.

When forming by semi-dry pressing, the ratio $\mathrm{S}: \mathrm{L}=3.6-5: 1 \mathrm{wt}$. $\mathrm{h}$. The molding mass was poured into molds and pressed at different pressures on a hydraulic press PLG-20. The products were dried according to the mode described above, followed by heat treatment at $700^{\circ} \mathrm{C}$ for 30 minutes.

The chemical composition of raw materials was determined using a Hitachi TM-1000 scanning electron microscope equipped with a TM1000 EDS detector. For samples of construction products, the dependence of the compressive and flexural strength on the heat treatment modes was studied. Physic-mechanical parameters were determined in accordance with the following standards: bending and compressive strength - GOST 846285, abrasion - GOST 13087-81, softening coefficient (water resistance) - GOST 30629-99.

\section{Results and discussion}

Slip casting technique. The studies showed that the rate of increase in the strength of the developed products significantly depends on the processing temperature and the time of their exposure. Formed products, both on the basis of sand and chamotte, when hardened under normal conditions $\left(20^{\circ} \mathrm{C}\right)$, gain strength very slowly (Table 2$)$. For 60 days of exposure under normal conditions, the compressive strength of sand-based products is 50.0 $\mathrm{MPa}$, when bending $-14.5 \mathrm{MPa}$, on the basis of chamotte $-53.0 \mathrm{MPa}$ and $12.9 \mathrm{MPa}$, respectively. 
Table 2. Characteristics of building materials (slip casting, temperature of hardening $20^{\circ} \mathrm{C}$ ).

\begin{tabular}{|c|c|c|c|}
\hline \multirow{3}{*}{ Filler } & \multirow{2}{*}{ Exposure time, day } & \multicolumn{2}{|c|}{ Strength, MPa } \\
\cline { 2 - 4 } & & compression & bending \\
\hline \multirow{4}{*}{ Chamotte } & 7 & 24 & 7.9 \\
\cline { 2 - 4 } & 9 & 55 & 10.0 \\
\cline { 2 - 4 } & 11 & 65 & 12.6 \\
\cline { 2 - 4 } & 14 & 68 & 14.0 \\
\cline { 2 - 4 } & 17 & 70 & 16.0 \\
\cline { 2 - 4 } & 18 & 72 & 16.0 \\
\hline \multirow{5}{*}{ Sand } & 21 & 72 & 16.5 \\
\cline { 2 - 4 } & 7 & 33 & 8.6 \\
\cline { 2 - 4 } & 9 & 39 & 10.4 \\
\cline { 2 - 4 } & 11 & 42 & 11.1 \\
\cline { 2 - 4 } & 14 & 56 & 13.4 \\
\cline { 2 - 4 } & 17 & 61 & 14.3 \\
\cline { 2 - 4 } & 18 & 65 & 14.9 \\
\hline
\end{tabular}

An increase in temperature significantly accelerates the hardening process of products (Table 3). An increase in the processing temperature of products to $50^{\circ} \mathrm{C}$, in which sand was used as a filler, allows you to get the compressive strength value for 15 days, and with chamotte - for 9 days of exposure, which in the case of hardening of products under normal conditions is achieved for 60 days. The strength set has been completed on 21 days, and the developed products had the following physical and mechanical characteristics: compressive strength of sand-based samples - 68.0 MPa, chamotte-based samples - $72.5 \mathrm{MPa}$; the bending strength is $15.3 \mathrm{MPa}$ and $16.5 \mathrm{MPa}$, respectively.

Table 3. Characteristics of building materials (slip casting, temperature of hardening $50^{\circ} \mathrm{C}$ ).

\begin{tabular}{|c|c|c|c|}
\hline \multirow{3}{*}{ Filler } & \multirow{2}{*}{ Exposure time, day } & \multicolumn{2}{|c|}{ Strength, MPa } \\
\cline { 2 - 4 } & & compression & bending \\
\hline \multirow{4}{*}{ Chamotte } & 21 & 2.6 & 0.8 \\
\cline { 2 - 4 } & 28 & 11.6 & 2.3 \\
\cline { 2 - 4 } & 35 & 23.3 & 7.2 \\
\cline { 2 - 4 } & 42 & 36.7 & 9.3 \\
\cline { 2 - 4 } & 49 & 45.0 & 10.3 \\
\cline { 2 - 4 } & 56 & 52.9 & 12.8 \\
\hline \multirow{4}{*}{ Sand } & 60 & 53.0 & 12.9 \\
\cline { 2 - 4 } & 21 & 12.1 & 3.4 \\
\cline { 2 - 4 } & 28 & 20.2 & 4.7 \\
\cline { 2 - 4 } & 35 & 28.4 & 6.5 \\
\cline { 2 - 4 } & 42 & 36.2 & 8.0 \\
\cline { 2 - 4 } & 49 & 48.1 & 11.4 \\
\cline { 2 - 4 } & 56 & 49.1 & 14.4 \\
\hline
\end{tabular}

Under the above-mentioned hardening conditions, the strength of the products is mainly due to the dehydration of the binder with the formation of a hardening structure. At elevated temperatures, the strength of the products also depends on the reactivity of the silica and alumina components of the fillers relative to the binder. 
For products based on chamotte, which were first dried at $50^{\circ} \mathrm{C}$ for 24 hours, and then heat-treated at an elevated temperature $\left(150^{\circ} \mathrm{C}\right.$ and above) with an exposure of 6 hours, a significant increase in compressive strength is observed (Table 4) compared to samples of similar composition under other heat treatment modes. This is due to the fact that as a result of sintering kaolinite clays into chamotte, $40-60 \%$ of silica glass is formed, which at elevated temperature dissolves in an alkaline medium [6]. In addition, the presence of aluminum oxide in the composition of chamotte in an amount of more than $30 \%$ (Table 1) leads to the synthesis of alkaline hydroaluminosilicates when mixing the silicate binder and filler. Thus, the chamotte in the resulting composition acts as an active structure-forming component, the reactivity of the silica and alumina components of which is significantly lower relative to the binder at normal temperature than at high temperature.

For products based on sand, such an obvious dependence of strength on the heat treatment mode was not revealed (strength at a processing temperature of $700^{\circ} \mathrm{C}$ was 69.5 $\mathrm{MPa}$, and at $50{ }^{\circ} \mathrm{C}$ it was $68.0 \mathrm{MPa}$ ), which indicates the inertia of the filler relative to the binder.

Table 4 shows the comparative characteristics of products obtained by the method of slip casting, depending on the temperature and time of heat treatment, which allow us to conclude that the greatest strength of the developed products can be achieved by applying either heat treatment at an elevated temperature $\left(150-700^{\circ} \mathrm{C}\right)$ or when the products are hardened for at least 21 days at $50^{\circ} \mathrm{C}$, in the latter case, the products do not have water resistance, so it is assumed that they are used in conditions of low humidity.

Table 4. Characteristics of building materials at different processing temperature (slip casting).

\begin{tabular}{|c|c|c|c|c|c|c|}
\hline \multirow{2}{*}{ Filler } & \multirow{2}{*}{$\begin{array}{c}\text { Processing } \\
\text { temperature, } \\
{ }^{\circ} \mathbf{C}\end{array}$} & \multirow{2}{*}{$\begin{array}{c}\text { Exposure } \\
\text { time }\end{array}$} & \multicolumn{2}{|c|}{ Strength, MPa } & \multirow{2}{*}{$\begin{array}{c}\text { Abrasion, } \\
\text { g/cm }\end{array}$} & \multirow{2}{*}{$\begin{array}{l}\text { Softening } \\
\text { coefficient }\end{array}$} \\
\hline & & & compression & bending & & \\
\hline \multirow{5}{*}{ Chamotte } & 20 & $\begin{array}{l}60 \text { days from } \\
\text { the moment } \\
\text { of filling }\end{array}$ & 53.0 & 12.9 & 0.20 & - \\
\hline & 50 & $\begin{array}{l}21 \text { days from } \\
\text { the moment } \\
\text { of filling }\end{array}$ & 72.5 & 16.5 & 0.34 & - \\
\hline & 150 & 6 hours & 58.3 & 8.1 & - & 0.70 \\
\hline & 300 & 6 hours & 91.2 & 8.2 & - & 0.72 \\
\hline & 700 & 6 hours & 95.9 & 12.2 & 0.36 & 0.75 \\
\hline \multirow{4}{*}{ Sand } & 20 & $\begin{array}{l}60 \text { days from } \\
\text { the moment } \\
\text { of filling }\end{array}$ & 50.0 & 14.5 & 0.39 & - \\
\hline & 50 & $\begin{array}{l}21 \text { days from } \\
\text { the moment } \\
\text { of filling }\end{array}$ & 68.0 & 15.3 & 0.33 & - \\
\hline & 300 & 6 hours & 57.0 & 8.9 & - & 0.69 \\
\hline & 700 & 6 hours & 69.5 & 8.5 & 0.15 & 0.71 \\
\hline
\end{tabular}

Semi-dry pressing method. Table 5 shows the characteristics of samples obtained at different ratios of filler and binder (S:L, wt. h.) and different pressing pressures. humidity. 
Table 5. Characteristics of building materials (semi-dry pressing, processing temperature is $700^{\circ} \mathrm{C}$ ).

\begin{tabular}{|c|c|c|c|c|}
\hline \multirow{3}{*}{ Filler } & \multirow{2}{*}{ Pressing pressure, MPa } & \multicolumn{3}{|c|}{ Compression strength, MPa } \\
\cline { 2 - 5 } & & $\mathbf{( S : L = 5 : 1 )}$ & $\mathbf{( S : L = 4 : 1 )}$ & (S:L =3.6:1) \\
\hline \multirow{5}{*}{ Sand } & 2 & 18.3 & 20.7 & - \\
\cline { 2 - 5 } & 4 & 20.0 & 32.3 & - \\
\cline { 2 - 5 } & 6 & 21.2 & 32.6 & - \\
\cline { 2 - 5 } & 8 & 23.3 & 27.7 & - \\
\cline { 2 - 5 } & 10 & 23.7 & 27.4 & - \\
\cline { 2 - 5 } & 12 & 24.0 & - & - \\
\cline { 2 - 5 } & 14 & 28.3 & - & - \\
\hline \multirow{5}{*}{ Chamotte } & 16 & 29.5 & - & 41.7 \\
\cline { 2 - 5 } & 2 & 29.1 & 26.0 & 43.5 \\
\cline { 2 - 5 } & 4 & 24.3 & 26.4 & - \\
\cline { 2 - 5 } & 5 & 25.6 & 26.3 & - \\
\hline
\end{tabular}

The analysis of Table 5 shows that at the ratio $\mathrm{S}: \mathrm{L}=5: 1$ an increase in the pressing pressure leads to an increase in the strength of the products, regardless of the nature of the filler. As the humidity increases, the strength at a single pressing pressure also increases. It is determined that the optimal pressing pressure at the ratio $\mathrm{S}: \mathrm{L}=4: 1$ for samples based on chamotte is $4 \mathrm{MPa}$, on the basis of sand- $6 \mathrm{MPa}$, while the compressive strength is $32.6 \mathrm{MPa}$ and $33.5 \mathrm{MPa}$, respectively. A further increase in the pressing pressure leads to the squeezing of the binder and to the heterogeneous structure of the resulting products, as a result of which their strength decreases. At $\mathrm{S}: \mathrm{L}=3.6: 1$ the optimal pressing pressure for samples based on chamotte is $5 \mathrm{MPa}$, the compressive strength is $43.5 \mathrm{MPa}$.

Analyzing the data obtained, it can be concluded that by varying the parameters of the technological cycle (pressing pressure) and the formulation of the molding mixture (S:L) it is possible to obtain building materials with a wide range of compressive strength (from 18.3 to $32.6 \mathrm{MPa}$ for sand- based samples and from 19.1 to $43.5 \mathrm{MPa}$ for chamotte-based samples).

A comparative analysis of the characteristics of building materials used in modern construction (ordinary ceramic brick M100-M300 (GOST 530-2012); ceramic clinker brick M300-M1000 (GOST 530-2012); silicate brick M300 (GOST 379-95)) with the characteristics of the materials obtained in this work showed that the latter can be recommended as structural products.

\section{Conclusions}

Based on silicate binder synthesized from dinas refractory scrap and aluminosilicate raw materials of various origins (waste of chamotte refractory, mineral raw materials (sand)) compositions for obtaining construction products for structural purposes have been developed.

The possibilities of forecasting and directional control of the kinetics of strength gain and physical and mechanical characteristics of the products by changing the technological and recipe parameters of production (molding method, heat treatment parameters, holding time, the ratio of filler and binder) have been revealed.

It was established that with an increase in the processing temperature from $20{ }^{\circ} \mathrm{C}$ to $50{ }^{\circ} \mathrm{C}$, the hardening process is intensified and the time of strength gain of building materials obtained by the method of slip casting is reduced from 60 to 21 days, respectively. 
The possibility of obtaining building materials with a wide range of operational properties by slip casting methods (compressive strength, samples based on chamotte 53,095,9 MPa; sand - 50.0-69.5 MPa; bending strength - 8.1-16.5 MPa; 8.5-15.3 MPa; abrasion, $\mathrm{g} / \mathrm{cm}^{2},-0.2-0.36 ; 0.15-0.39$, respectively) and semi-dry pressing (compressive strength of samples based on chamotte 19.1...43.5 MPa; sand - 18.3...32.6 MPa).

This work was supported by the Ministry of Science and Higher Education of the Russian Federation within the governmental order for Institute of Solid State Chemistry and Mechanochemistry of SB RAS (project(s) FWUS-2021-0004).

\section{References}

1. K.A. Cherepanov, K.M. Kulagin, Z.A. Maslovskaya, Izvestia Universities. Black metallurgy 6, 67 (1999)

2. K.A. Cherepanov, M.V. Temlantsev, E.N. Temlantseva, A.A. Terere, Izvestia universities. Black metallurgy 12, 69 (2004)

3. V.I. Entin, V.D. Shelogubov, New refractories 5, 32 (2005)

4. Federal Classification Catalog of Waste [Electronic Resource]: Access Mode http://kod-fkko.ru/kod-91219511404-mertel-shamotnyy-alyumosilikatnyy/.

5. L.K. Berdnikova, V.A. Poluboyarov, Z.A. Korotaeva, F.K. Gorbunov, V.V. Bulgakov, Inorg. Mater. Appl. Res. 4, 1008 (2020)

6. V.A. Avakov, Build. Mater. 11, 35 (1972) 